\title{
Changes in plasma phenylalanine, isoleucine, leucine, and valine are associated with significant changes in intracranial pressure and jugular venous oxygen saturation in patients with severe traumatic brain injury
}

\author{
Vuille-Dit-Bille, R N ; Ha-Huy, R ; Stover, J F
}

\begin{abstract}
Changes in plasma aromatic amino acids (AAA = phenylalanine, tryptophan, tyrosine) and branched chain amino acids (BCAA = isoleucine, leucine, valine) levels possibly influencing intracranial pressure (ICP) and cerebral oxygen consumption $(\operatorname{SjvO}(2))$ were investigated in 19 sedated patients up to 14 days following severe traumatic brain injury (TBI). Compared to 44 healthy volunteers, jugular venous plasma BCAA were significantly decreased by $35 \%(\mathrm{p}<0.001)$ while AAA were markedly increased in TBI patients by $19 \%(\mathrm{p}<0.001)$. The BCAA to AAA ratio was significantly decreased by $55 \%$ (p < 0.001 ) which persisted during the entire study period. Elevated plasma phenylalanine was associated with decreased ICP and increased $\mathrm{SjvO}(2)$, while higher plasma isoleucine and leucine levels were associated with increased ICP and higher plasma leucine and valine were linked to decreased $\mathrm{SjvO}(2)$. The amount of enterally administered amino acids was associated with significantly increased plasma levels with the exception of phenylalanine. Contrary to the initial assumption that elevated AAA and decreased BCAA levels are detrimental, increased plasma phenylalanine levels were associated with beneficial signs in terms of decreased ICP and reduced cerebral oxygen consumption reflected by increased $\mathrm{SjvO}(2)$; concomitantly, elevated plasma isoleucine and leucine levels were associated with increased ICP while leucine and valine were associated with decreased $\mathrm{SjvO}(2)$ following severe TBI, respectively. The impact of enteral nutrition on this observed pattern must be examined prospectively to determine if higher amounts of phenylalanine should be administered to promote beneficial effects on brain metabolism and if normalization of plasma BCAA levels is without cerebral side effects.
\end{abstract}

DOI: https://doi.org/10.1007/s00726-011-1202-x

Posted at the Zurich Open Repository and Archive, University of Zurich

ZORA URL: https://doi.org/10.5167/uzh-59750

Journal Article

Published Version

Originally published at:

Vuille-Dit-Bille, R N; Ha-Huy, R; Stover, J F (2012). Changes in plasma phenylalanine, isoleucine, leucine, and valine are associated with significant changes in intracranial pressure and jugular venous oxygen saturation in patients with severe traumatic brain injury. Amino Acids, 43(3):1287-1296.

DOI: https://doi.org/10.1007/s00726-011-1202-x 


\title{
Changes in plasma phenylalanine, isoleucine, leucine, and valine are associated with significant changes in intracranial pressure and jugular venous oxygen saturation in patients with severe traumatic brain injury
}

\author{
Raphael N. Vuille-Dit-Bille • Riem Ha-Huy • \\ John F. Stover
}

Received: 21 July 2011/Accepted: 9 December 2011/Published online: 22 December 2011

(C) Springer-Verlag 2011

\begin{abstract}
Changes in plasma aromatic amino acids (AAA = phenylalanine, tryptophan, tyrosine) and branched chain amino acids $(\mathrm{BCAA}=$ isoleucine, leucine, valine) levels possibly influencing intracranial pressure (ICP) and cerebral oxygen consumption $\left(\mathrm{SjvO}_{2}\right)$ were investigated in 19 sedated patients up to 14 days following severe traumatic brain injury (TBI). Compared to 44 healthy volunteers, jugular venous plasma BCAA were significantly decreased by $35 \%(p<0.001)$ while AAA were markedly increased in TBI patients by $19 \%(p<0.001)$. The BCAA to AAA ratio was significantly decreased by $55 \%(p<0.001)$ which persisted during the entire study period. Elevated plasma phenylalanine was associated with decreased ICP and increased $\mathrm{SjvO}_{2}$, while higher plasma isoleucine and leucine levels were associated with increased ICP and higher plasma leucine and valine were linked to decreased $\mathrm{SjvO}_{2}$. The amount of enterally administered amino acids was associated with significantly increased plasma levels with the exception of phenylalanine. Contrary to the initial assumption that elevated AAA and decreased BCAA levels are detrimental, increased plasma phenylalanine levels were associated with beneficial signs in terms of decreased ICP and reduced cerebral oxygen consumption reflected by increased $\mathrm{SjvO}_{2}$; concomitantly, elevated plasma isoleucine and leucine levels were associated with increased ICP while leucine and valine were associated with decreased $\mathrm{SjvO}_{2}$ following severe TBI, respectively. The impact of enteral nutrition on this observed pattern must be examined prospectively to determine if higher amounts of phenylalanine should be administered to promote beneficial
\end{abstract}

R. N. Vuille-Dit-Bille · R. Ha-Huy · J. F. Stover $(\bowtie)$

Surgical Intensive Care Medicine, UniversitätsSpital Zürich, 8091 Zurich, Switzerland

e-mail: john.stover@access.uzh.ch effects on brain metabolism and if normalization of plasma BCAA levels is without cerebral side effects.

Keywords Critical care $\cdot$ Monitoring $\cdot$ Neuromonitoring · Nutrition

\section{Introduction}

Following traumatic brain injury (TBI) a cascade of secondary events, including, among others, amino acid-mediated excitotoxicity, may promote secondary brain edema formation with consecutive clinical deterioration and increased intracranial pressure (ICP). Consequently, prevention of secondary brain damage is the main therapeutic target in contemporary intensive care treatment (Stover et al. 2005). In this context, diminished $\mathrm{SjvO}_{2}$ reflects cerebral metabolic impairment and insufficient cerebral perfusion (Robertson et al. 1995).

Stressful events are associated with significant increases in plasma aromatic amino acids (AAA), i.e., phenylalanine (Phe), tryptophan (Trp) and tyrosine (Tyr) and significant decreases in branched chain amino acids (BCAA), i.e., valine (Val), leucine (Leu) and isoleucine (Ile) (Freund et al. 1978, 1979, 1982; Stinnett et al. 1982; Vente et al. 1989; Basler et al. 2002; Blomstrand et al. 2005; Dejong et al. 2007).

Imbalances between plasma BCAA and AAA levels are known to contribute to metabolic encephalopathy as observed following liver failure. In this context, Tyr and Phe enhance synthesis of physiologic excitatory adrenergic neurotransmitters (dopamine, norepinephrine, and epinephrine) (Fernstrom and Fernstrom 2007) and so-called false neurotransmitters (phenylethanolamine and octopamine) which may also mediate neuronal excitation (Cangiano 
et al. 1982). Tyr promotes serotonin synthesis (Fernstrom and Fernstrom 2007; Daubert and Condron 2010).

Since AAA and BCAA compete for the same amino acid transporter within the $\mathrm{BBB}$, a reduction in $\mathrm{BCAA}$ plasma levels further increases cerebral AAA uptake. Sustained cerebral AAA uptake with subsequent increased synthesis of excitatory amino acids could promote excessive neuronal excitation. This, in turn, could facilitate metabolic impairment reflected e.g., by decreased $\mathrm{SjvO}_{2}$ and result in sustained edema formation unmasked e.g., by increased ICP. Whether TBI patients also show an imbalance between AAA and BCAA and if changes in plasma AAA and BCAA concentrations are possibly associated with increased cerebral oxygen consumption and elevated ICP, thereby expanding contemporary neuromonitoring (Stover 2011) has not been investigated yet.

To test the hypothesis that changes in plasma AAA and BCAA influence $\mathrm{SjvO}_{2}$ and ICP we performed the current retrospective analysis. In addition, we investigated if the composition of an enteral nutrition solution as used in clinical routine influences plasma AAA and BCAA. For this, we measured plasma concentrations of AAA (Phe, Trp and Tyr) and BCAA (Ile, Leu and Val) in 19 TBI patients subjected to pharmacologic coma for up to 2 weeks. The plasma amino acid levels were compared to the results obtained in 44 healthy volunteers. Influence of enteral nutrition on plasma AAA and BCAA levels was assessed by linear regression analysis. Possible pathologic impact of changes in AAA and BCAA values was assessed by correlation with ICP and $\mathrm{SjvO}_{2}$ values.

\section{Materials and methods}

This study was approved by the local ethics committee and written informed consent was obtained by the relatives of the TBI patients and the volunteers, respectively.

Patients with severe traumatic brain injury

Following TBI jugular venous plasma was collected daily up to 14 days. For this, a catheter was inserted in the internal jugular vein with the tip positioned in the jugular bulb of the dominant internal jugular vein. The correct localization was verified by lateral X-ray of the skull. A total of 121 plasma samples were collected. Patients older than 65 and younger than 16 years were excluded as well as patients with a known history of seizure disorders, depression, alcohol or drug abuse, renal or hepatic dysfunction, metabolic disorders or previous history of TBI. Patients suffering from severe abdominal injury requiring surgery or constipation, in whom enteral nutrition could not be performed, those who were anticipated to die within the first $24 \mathrm{~h}$, and patients in need of barbiturate coma to treat intractable intracranial hypertension were not included.

TBI patients were treated using a standardized treatment protocol as reported previously (Vuille-Dit-Bille et al. 2011). For sedation and analgesia, midazolam (Dormicum $^{\circledR}$ ) and fentanyl (Sintenyl ${ }^{\circledR}$ ) were infused continuously. Cerebral perfusion pressure (CPP) was maintained above $60 \mathrm{mmHg}$ by infusing norepinephrine and crystalloids or colloids. Ventilation and oxygenation were guided by $\mathrm{SjvO}_{2}$ maintained above $60 \%$. TBI patients did not receive heparin or low molecular weight heparin (LMWH).

All patients were fed enterally according to our standardized protocol using Jevity ${ }^{\circledR}$ Plus (Abbott, Abbott Park, IL, 60064-3500, USA) which was started with $20 \mathrm{ml} / \mathrm{h}$ within the first $12 \mathrm{~h}$ and increased by $10 \mathrm{ml} / \mathrm{h}$ every $6 \mathrm{~h}$, reaching target volume and calories within $30 \mathrm{~h}$. Individual dose was adjusted to meet caloric requirement determined by indirect calorimetry which was performed twice every week. According to the manufacturer's manual Jevity ${ }^{\circledR}$ Plus contains Phe 2,700 mg/l, Tyr 2,700 mg/l, Trp 60 mg/l, Ile 2,500 mg/l, Leu 4,900 mg/l, and Val 3,100 mg/l, with an increased BCAA to AAA ratio (1.9:1).

\section{Healthy volunteers}

A total of 44 volunteers (22 males, 22 females, aged mean \pm SD $37.2 \pm 10.4$, range $22-56$ years) were included in this study. Blood was drawn once from the cubital vein in the morning between 8:00 a.m. and 09:00 a.m. after overnight fasting. Volunteers with recent history of fever, surgery or drug intake (e.g., antibiotics, anti-depressants, sedatives, analgetics, platelet aggregation inhibitors) were excluded.

Analysis of plasma amino acids and calculation of Fischer ratio

Jugular venous blood was drawn in the morning between 8:00 a.m. and 09:00 a.m. during enteral nutrition, comparable to healthy volunteers to correct for possible circadian changes.

In addition to jugular venous plasma, arterial plasma was also analyzed at the same time points. However, arterial-jugular venous differences were not significant; since arterial blood had not been drawn from the volunteers, the patients' arterial results are not presented.

Concentrations of amino acids were determined by high performance liquid chromatography (HPLC) as reported previously (Vuille-Dit-Bille et al. 2011).

The calculated BCAA to AAA ratio, referred to as the Fischer ratio (Fischer et al. 1976; Miyazaki et al. 2003) is widely used to assess amino acid-related metabolic encephalopathy as found e.g., in hepatic dysfunction. The Fischer ratio was calculated by dividing the sum of BCAA, 
i.e., Ile, Leu, and Val through the sum of Phe and Tyr. With increasing plasma Phe and Tyr levels, the Fischer ratio will decrease while elevated BCAA levels will increase the calculated Fischer ratio.

Treatment of patients was not influenced by this study or hereby obtained results.

\section{Statistical analysis}

Results are shown as mean $\pm \mathrm{SD}$ (standard deviation). Differences between groups were analyzed using unpaired students $t$ test or one-way analysis of variance (ANOVA) with post hoc multiple comparison. Correlation was performed by linear regression analysis. Changes were considered significant at $p$ values $<0.05$. Graphic and statistical analysis was performed using SigmaPlot10 ${ }^{\circledR}$ (Systat Software Inc).

\section{Results}

Patient data and impact of additional injuries and complications on plasma amino acid levels

A total of 19 patients consisting of 17 males and two females, of whom nine presented with isolated TBI were

Table 1 Demographic data of the investigated 19 patients suffering from severe traumatic brain injury requiring continuous pharmacologic coma and receiving standard enteral nutrition with Jevity ${ }^{\circledR}$ Plus

\begin{tabular}{ll}
\hline $\begin{array}{l}\text { Age (mean } \pm \text { SD; median, } \\
\text { range) }\end{array}$ & $39.2 \pm 13.0(41,18-64)$ \\
Gender (female/male) & $2 / 17(89 / 11 \%)$ \\
GCSi & $9 \pm 4(9,3-15)$ \\
AIS head & $4.8 \pm 0.5(5,3-5)$ \\
ISS excluding AIS head & $6.5 \pm 7.8(3,0-20)$ \\
& 9 isolated TBI \\
& 2 thoracic injury and femur fracture \\
& 1 combined abdominal and thoracic \\
& injury \\
& 1 abdominal injury and femur \\
& 4 fracture \\
& 2 humerus fractures \\
& $24 \pm 14(21,6-54)$ \\
Days on ICU & 8 pneumonia \\
Complications & 2 urinary tract infections \\
eGOS at 6 months & $5.8 \pm 1.8(6,2-8)$
\end{tabular}

Results are given as mean \pm standard deviation with median and range

ICU intensive care unit, eGOS extended Glasgow Outcome Scale, $G C S i$ initial Glasgow Coma Scale, AIS abbreviated Injury Score, ISS Injury Severity Score included in this study (Table 1). Plasma amino acid levels were not influenced by the additional injuries and complications observed during the 14-day observational period (data not shown). Treatment measures determined by the therapy intensity level taken to lower increased ICP were similar in both weeks (Table 1).

Changes in plasma branched chain amino acids

Compared to healthy controls, plasma Ile, Leu, and Val concentrations were significantly decreased during the first week following severe TBI. During the second posttraumatic week, BCAA levels showed a non-significant trend to higher values with Leu and Val remaining significantly decreased compared to healthy volunteers (Fig. 1a).

Changes in plasma aromatic amino acids

Compared to healthy controls, plasma Tyr was significantly increased during both posttraumatic weeks; Phe was significantly increased during the first posttraumatic week and Trp showed a non-significant trend to higher values over time (Fig. 1b).

Changes in calculated arterial-jugular venous differences

Calculated arterial-jugular venous differences in plasma amino acids were not significantly changed over time or influenced by the enteral nutrition (data not shown).

Influence of enteral nutrition on plasma amino acid concentrations

All patients received Jevity ${ }^{\circledR}$ Plus as our standard enteral nutrition (Table 2). In the second week, patients received significantly higher amount of enteral nutrition, thereby resulting in significantly more calories (Table 2). On average, patients received $23 \mathrm{kcal} / \mathrm{kg} /$ day in the second week compared to $19 \mathrm{kcal} / \mathrm{kg} /$ day during the first week (Table 2).

With the specific composition of Jevity ${ }^{\circledR}$ Plus, patients received on average Phe $3325 \pm 128 \mathrm{mg} /$ day, Tyr $3324 \pm$ $128 \mathrm{mg} /$ day, Trp $74 \pm 3 \mathrm{mg} /$ day, Ile $3078 \pm 118 \mathrm{mg} /$ day, Leu $6034 \pm 232 \mathrm{mg} / \mathrm{day}$, and Val $3817 \pm 147 \mathrm{mg} /$ day, respectively.

While plasma Tyr $[\mathrm{Tyr}=43.428+(0.0194 \times$ Jevity $)$ $\left.R^{2}=0.129 ; p<0.0001\right], \operatorname{Trp}[\operatorname{Trp}=30.993+(0.00979 \times$ Jevity), $\left.R^{2}=0.07 ; \quad p=0.004\right], \quad$ Ile $\quad[$ Ile $=23.839+$ $(0.0113 \times$ Jevity $\left.), R^{2}=0.136 ; p<0.001\right]$, Leu [Leu $=$ $77.286+(0.0160 \times$ Jevity $\left.), R^{2}=0.079 ; p=0.002\right]$, and Val $\quad\left[\right.$ Val $=105.149+(0.0386 \times$ Jevity $), \quad R^{2}=0.144 ;$ 


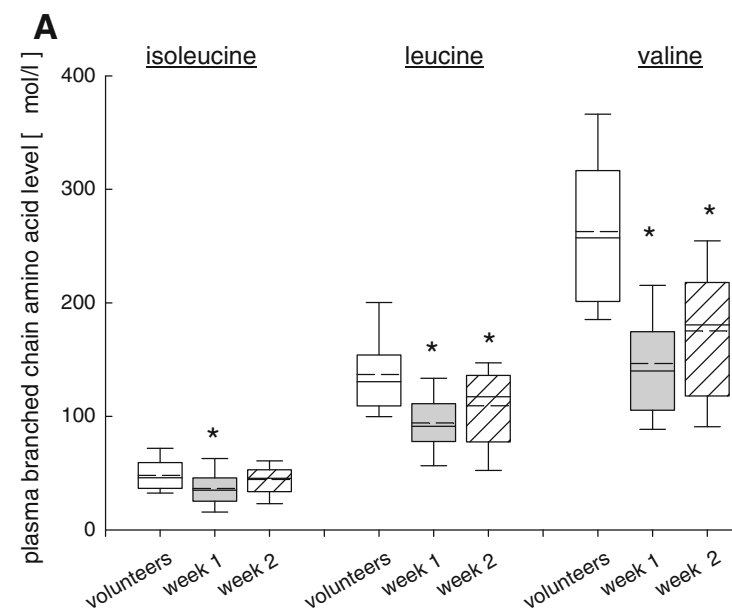

Fig. 1 Changes in branched chain amino acids and aromatic amino acids during the first two posttraumatic weeks in 19 sedated patients with severe traumatic brain injury represented as box plots (solid line median, dashed line mean, box limits 25th and 75th percentile, whiskers 5th and 95th percentile). Plasma Ile, Leu, and Val levels

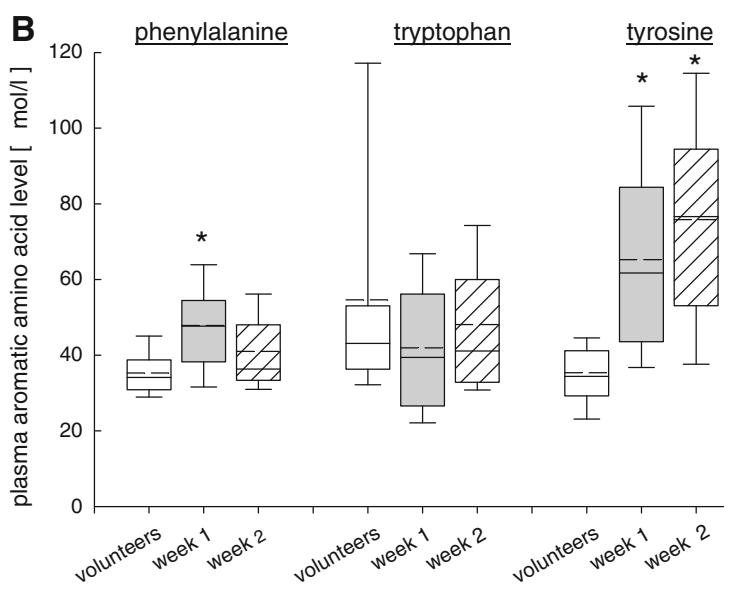

were significantly decreased compared to healthy volunteers ( $p<0.001$, ANOVA with post hoc Dunn's test). Plasma Phe and Tyr were significantly increased compared to healthy controls $(p<0.001$, ANOVA with post hoc Dunn's test). There were no significant differences between the first and second week

Table 2 Changes in intracranial pressure (ICP), cerebral perfusion pressure (CPP), $\mathrm{paCO}_{2}$, temperature, and enteral nutrition during the first 2 weeks in 19 patients with severe traumatic brain injury

\begin{tabular}{lcr}
\hline & week 1 & week 2 \\
\hline $\mathrm{ICP}(\mathrm{mmHg})$ & $15 \pm 5(15,6-27)$ & $18 \pm 4(19,12-27)$ \\
$\mathrm{CPP}(\mathrm{mmHg})$ & $82 \pm 5(82,66-97)$ & $80 \pm 8(80,71-114)$ \\
$\mathrm{paCO}_{2}(\mathrm{kPa})$ & $4.95 \pm 0.7(5,4.2-5.8)$ & $4.86 \pm 0.8(4.9,4-5.6)$ \\
Temperature $\left({ }^{\circ} \mathrm{C}\right)$ & $35.7 \pm 0.9(35.5,34.4-36.7)$ & $35.5 \pm 0.6(35.8,34.9-36.6)$ \\
Therapy intensity level (TIL) & $2 \pm 0.8(2.6,2-4)$ & $2 \pm 0.8(2.7,2-4)$ \\
Jevity ${ }^{\circledR}$ Plus $(\mathrm{ml} /$ day $)$ & $1,183 \pm 498(1,300,60-2,200)$ & $1,444 \pm 476^{*}(1,550,150-2,300)$ \\
$\mathrm{kcal} /$ day & $1420 \pm 590(1,560,72-2,640)$ & $1,733 \pm 490(1,860,180-2,760)^{*}$ \\
Average $\mathrm{kcal} / \mathrm{kg} /$ day & 19 & $23^{*}$
\end{tabular}

In the second week, the patients received significantly more calories, reflected by significantly increased amount of Jevity ${ }^{\circledR}$ Plus $\left({ }^{*} p<0.02\right.$, Mann-Whitney test). Results are given as mean \pm standard deviation with median and range

$p<0.001]$ correlated significantly with the enterally administered amino acids, there was no significant correlation for plasma Phe (Fig. 2).

Branched chain and aromatic amino acids and $\mathrm{SjvO}_{2}$

Within the group of BCAA, elevated plasma Leu and Val levels significantly correlated with low $\mathrm{SjvO}_{2}$ (Fig. 3). Within the group of AAA, higher Phe significantly correlated with elevated $\mathrm{SjvO}_{2}$. Tyr, Trp, and Ile had no significant effect on $\mathrm{SjvO}_{2}$.

Branched chain and aromatic amino acids and ICP

Increased plasma Ile and Leu significantly correlated with elevated ICP (Fig. 4) while increased plasma Phe correlated significantly with lower ICP. Tyr, Trp, and Val had no significant effect on ICP.

Calculated Fischer ratio in patients and healthy volunteers

Fischer ratio reflecting imbalance between (Leu + $\mathrm{Ile}+\mathrm{Val}) /(\mathrm{Phe}+\mathrm{Tyr})$ remained significantly lower in TBI patients at all time points compared to healthy volunteers: $2.7 \pm 0.8$ (week 1), $3.1 \pm 0.2$ (week 2) versus $6.5 \pm 0.1(p<0.0001)$ (volunteers).

Correlation of calculated Fischer ratio with ICP and $\mathrm{SjvO}_{2}$

Increased calculated Fischer ratio correlated significantly with high ICP and significantly with low $\mathrm{SjvO}_{2}$ (Fig. 5). 


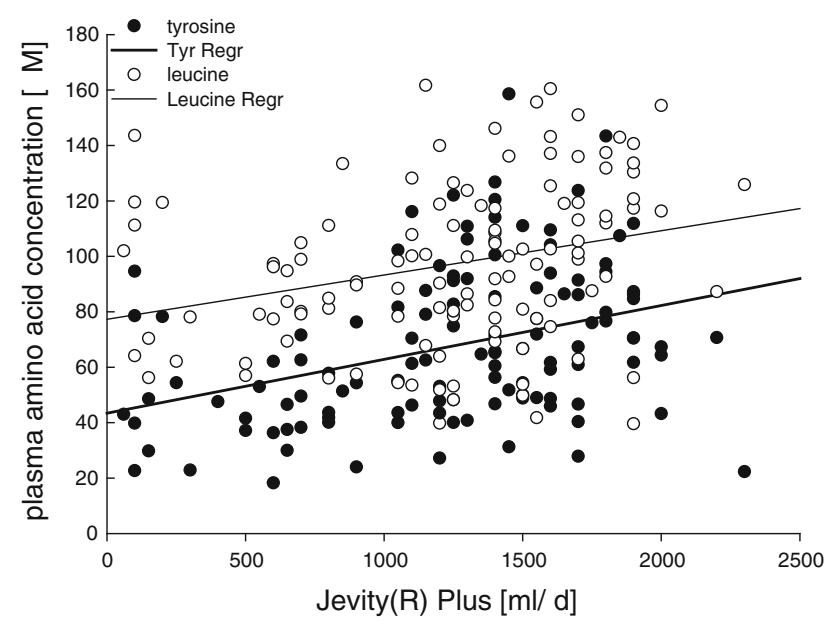

Fig. 2 Significant increase in plasma Leu [Leu $=77.286+$ $(0.0160 \times$ Jevity $\left.), \quad R^{2}=0.08, \quad p=0.002\right]$ and plasma $\mathrm{Tyr}$ $\left[\right.$ Tyr $=43.428+(0.0194 \times$ Jevity $\left.), R^{2}=0.129, p<0.001\right]$ representing the changes in branched chain amino acids and aromatic amino acids, respectively, was encountered at higher amounts of enterally administered Jevity ${ }^{\circledR} 1.5 \mathrm{cal}$
Changes in arterial blood glucose and insulin administration

During the first 2 weeks, arterial blood glucose remained within the pre-defined target $3.5-6.5 \mathrm{mmol} / \mathrm{l}$ without a significant difference between the first and second week (Table 2).

Insulin administration was similar during the first two posttraumatic weeks without a significant difference (Table 2).

Plasma amino acids were not influenced by the changes in blood glucose or insulin (data not shown).

\section{Discussion}

Following severe TBI, plasma BCAA were significantly decreased while AAA were markedly increased. The resulting significantly decreased Fischer ratio persisted during the first two posttraumatic weeks. While elevated

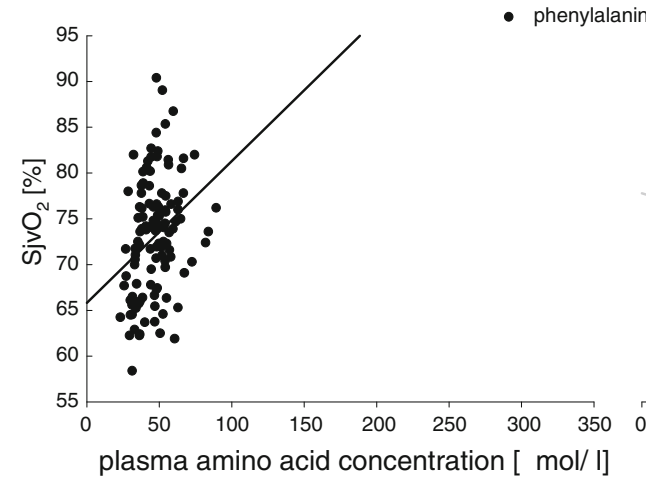

Fig. $3 \mathrm{SjvO}_{2}$ was significantly decreased at elevated plasma Leu and Val levels $\left[\mathrm{SjvO}_{2}=77.798-(0.0482 \times \mathrm{Leu}) ; R^{2}=0.0494, p=\right.$ $\left.0.018, \mathrm{SjvO}_{2}=77.262-(0.0302 \times \mathrm{Val}), R^{2}=0.0628, p=0.022\right]$ while $\mathrm{SjvO}_{2}$ was significantly increased at higher plasma Phe concentrations $\left[\mathrm{SjvO}_{2}=65.836+(0.155 \times \mathrm{Phe}), R^{2}=0.0940, p<\right.$ 0.001. Plasma Tyr, Trp, and Ile showed no significant effect on $\mathrm{SjvO}_{2}$

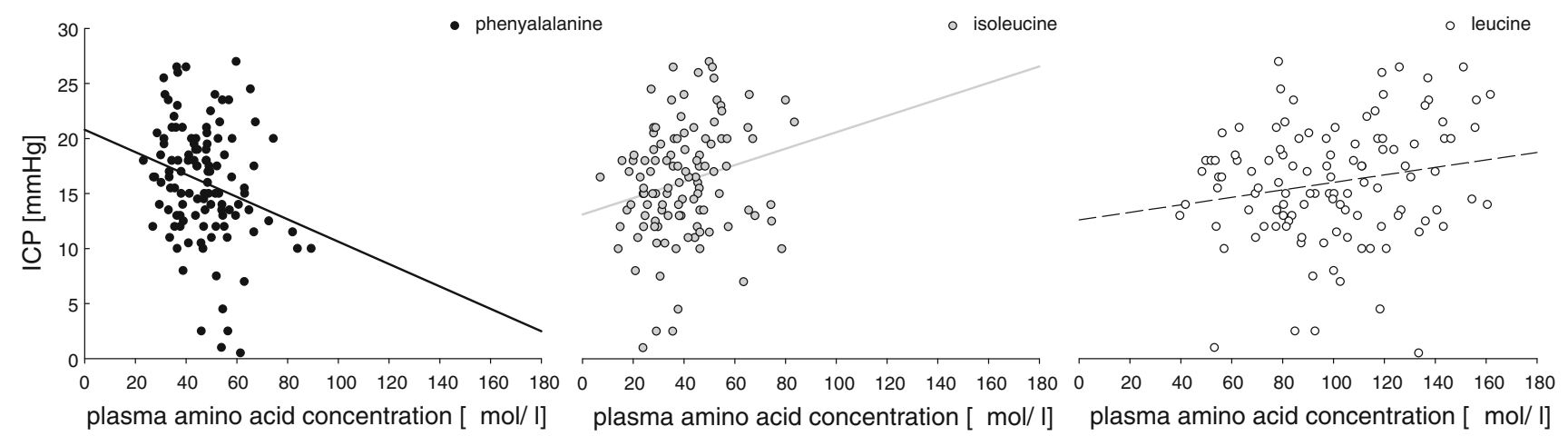

Fig. 4 ICP was significantly decreased at elevated plasma Phe $\left[\mathrm{ICP}=20.792-(0.102 \times \mathrm{Phe}), R^{2}=0.0583, p=0.010\right]$ while ICP was significantly increased at higher plasma Ile $[\mathrm{ICP}=13.115+$
$(0.0747 \times$ Ile $\left.) ; R^{2}=0.0489 ; p=0.021\right]$ and Leu $[\mathrm{ICP}=12.601+$ $(0.0341 \times$ Leu $\left.), R^{2}=0.0357, p=0.047\right]$ 


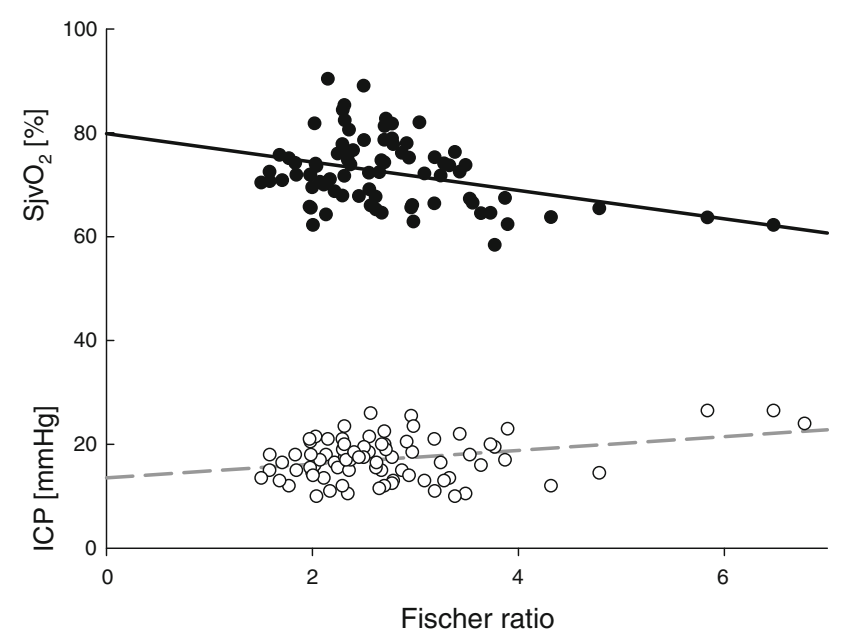

Fig. $5 \mathrm{SjvO}_{2}$ was significantly and inversely influenced by calculated Fischer ratio $\left[\mathrm{SjvO}_{2}=79.820-(2.733 \times \mathrm{FR}), R^{2}=0.127, p=\right.$ 0.001]. ICP was significantly influenced by the calculated Fischer ratio $\left[\mathrm{ICP}=13.527+(1.324 \times \mathrm{FR}), R^{2}=0.0987, p=0.005\right]$

plasma Phe was associated with significantly decreased ICP, higher plasma Ile and Leu were associated with significantly increased ICP. Concomitantly, elevated plasma Phe was associated with significantly increased $\mathrm{SjvO}_{2}$ while higher plasma Leu and Val levels were associated with markedly decreased $\mathrm{SjvO}_{2}$. The plasma pattern was influenced by the enterally administered amino acids. Cautious interpretation of this pattern suggests that (1) increased plasma BCAA levels might exert disadvantageous effects following severe TBI, (2) higher plasma Phe levels might be advantageous, and (3) enteral nutrition influences the plasma pattern.

\section{Importance of branched chain amino acids}

BCAA, especially leucine is an important regulator of protein synthesis (Avruch et al. 2009). BCAA promote ammonia detoxification, correct plasma amino acid imbalance, attenuate cerebral AAA influx, improve protein synthesis, glutamine production and inhibit proteolysis (Holecek 2010). In addition, BCAA support cardiac and skeletal muscle mitochondrial biogenesis, prevent oxidative damage, and enhance physical endurance (Valerio et al. 2011). Independent of hepatic encephalopathy plasma Leu, Ile, and Val levels also influence brain function by promoting glutamate compartmentalization, energy synthesis and most importantly by balancing the uptake of AAA, thereby controlling subsequent synthesis of excitatory monoaminergic neurotransmitters dopamine, noradrenaline, adrenaline, and serotonin from the AAA precursors Tyr and Trp, respectively (Fernstrom 2005). Under normal conditions, BCAA and AAA are transported by the same amino acid transporter (LAT1) across the $\mathrm{BBB}$, which is nearly fully saturated at physiologic plasma amino acid concentrations (Meier et al. 2002; Verrey 2003). In addition, BCAA improve recovery of cognition in a posttraumatic vegetative or minimally conscious state, most likely by increasing cerebral energy production, restoring ionic homeostasis, reducing membrane depolarization and attenuating neuronal injury, mostly in ischemic regions (Aquilani et al. 2005). However, oral ingestion of BCAA has been associated with neuropsychologic alterations related to reduced brain catecholamine synthesis and brain dopamine function (Scarnà et al. 2005).

In the present study, plasma BCAA levels were significantly decreased during the first posttraumatic week compared to healthy volunteers. Over time, the BCAA showed a different temporal profile: while Ile levels showed a trend to normalization in the second week, plasma Leu and Val concentrations remained significantly decreased. The persisting decrease in BCAA which occurred despite enteral nutrition contributed to a significant decrease in the calculated Fischer ratio maintained during the entire study period. This pattern is not specific for TBI but typical for critically ill patients (Freund et al. 1978, 1979, 1982; Vente et al. 1989; Basler et al. 2002; Dejong et al. 2007) which is not encountered in patients undergoing elective surgery (Askanazi et al. 1980a, b). Contrary to our present results, Petersen et al. (1996) could not show significant differences in the calculated Fischer ratio despite a significant decrease in all amino acids by $46 \%$. One possible reason could be the very aggressive nutritional strategy with $30 \mathrm{kcal} / \mathrm{kg}$ chosen by Petersen and coworkers compared to the slow increase in nutritional/caloric support as performed in our patients with an average of $19 \mathrm{kcal} / \mathrm{kg} /$ day during the first week gradually increased to $23 \mathrm{kcal} / \mathrm{kg} / \mathrm{day}$ in the second week. Unfortunately, Petersen and coworkers used different nutrition products without providing sufficient information as to their administration (Vital HN, Ross Laboratories; and Jevity, Ross Laboratories). Suzuki et al. (2002) investigated the changes in plasma amino acids during the first $24 \mathrm{~h}$ following TBI without, however, specifically addressing alterations in BCAA and AAA and without statistical comparison to blood samples taken from 101 healthy volunteers.

To date, the impact of an altered Fischer ratio following severe TBI has not been investigated. The present study is the first to unmask significant changes which also appear to be of functional relevance. In this context, linear regression analysis revealed a direct impact of plasma BCAA on ICP values and an indirect correlation with $\mathrm{SjvO}_{2}$ levels following severe TBI. These changes were mainly induced by Ile and Leu associated with increased ICP and Leu- and Val-associated decrease in $\mathrm{SjvO}_{2}$ values. These results suggest a more disadvantageous effect of BCAA compared to Phe which was associated with decreased ICP and 
increased $\mathrm{SjvO}_{2}$ values. Lower $\mathrm{SjvO}_{2}$ levels coinciding with higher Leu and Val levels suggest increased cerebral oxygen consumption possibly induced activation of protein synthesis, transport and uptake processes, and ammonia detoxification (Holecek 2010). Cerebral hypoxia/ischemia due to insufficient cerebral oxygenation, impaired CPP, or sustained hyperventilation can be excluded (Table 2), as $\mathrm{SjvO}_{2}$ remained above the ischemic threshold of 50\% and the other parameters were within pre-defined target range. This, in turn, favors an amino acid-driven influence. Sustained cerebral oxygen consumption and Leu-driven increased cerebral $\mathrm{CO}_{2}$ production (Chaplin et al., 1976) could result in increased cerebral vasodilation which, in turn, might explain the increased ICP at higher Ile and Leu levels. The present data does not allow to determine a possible Ile-, Leu- and Val-mediated edema-aggravating effect. However, length hospitalization, indirectly reflecting emerging complications, was not significantly influenced by these amino acids (linear regression analysis, data not shown). With the dose-dependent influence of amino acids provided by enteral nutrition on plasma concentrations, we could hypothesize that enteral nutrition could influence amino acid-mediated changes in ICP and $\mathrm{SjvO}_{2}$. This, however, must be investigated prospectively.

\section{Importance of aromatic amino acids (AAA)}

In the present study, plasma Tyr was increased during the first two posttraumatic weeks while Phe was only significantly increased during the first week. Physiologic as well as pathophysiologic effects of increased plasma AAA levels depend on the balancing effects mediated by BCAA (Fernstrom and Fernstrom 2007). Under physiologic conditions, Phe and Tyr are the precursors for subsequent synthesis of the excitatory neurotransmitters noradrenaline, adrenaline, and dopamine (Fernstrom and Fernstrom 2007). As shown in soldiers investigated under stressful conditions increased plasma Tyr levels reached during a tyrosine-enriched diet increased cerebral catecholamine synthesis, thereby promoting catecholamine-dependent effects, including regulation of blood pressure, thermoregulation as well as improved cognition and performance (Fernstrom 2000, Lieberman 2003). Transport of AAA and BCAA across the luminal and basolateral membrane of the BBB (Roberts et al. 2008) is mediated by the same large high affinity $\left(K_{\mathrm{m}} 15-50 \mu \mathrm{M}\right)$ transporter LAT1 for neutral amino acids (Meier et al. 2002; Verrey 2003). Due to the competition of different neutral amino acids for LAT1mediated transport, increases in plasma levels of one single amino acid may decrease cerebral uptake of other amino acids (Fernstrom and Fernstrom 2007) which as e.g., in phenylketonuria disturbs brain development (Blau et al. 2010). BCAA-rich diets which competitively reduce cerebral uptake of Tyr and Phe were associated with reduced dopamine synthesis and depression of different physiological and behavioral effects, including spatial recognition memory and physical performance (Scarnà et al. 2005, Fernstrom and Fernstrom 2007).

Sustained cerebral synthesis of AAA-derived excitatory neurotransmitters can promote transmitter-induced encephalopathy (Fernstrom 2005) which is feared to aggravate underlying traumatic brain damage due to augmented vulnerability. In addition, AAA-promoted synthesis of "false neurotransmitters" such as octopamine, phenylethanolamine, and tyramine are also associated with encephalopathic changes (Holecek 2010). Contrary to these potentially disadvantageous effects due to increased plasma AAA levels, linear regression analysis excluded signs of significant cerebral worsening: while Tyr and Trp showed no effect under the present conditions, elevated plasma Phe levels were associated with decreased ICP and increased $\mathrm{SjvO}_{2}$. In fact, the present study even suggests positive effects related to increased plasma Phe. Whether this is induced by the enteral nutrition must be investigated prospectively.

Possible impact of enteral nutrition on plasma amino acid levels

The present retrospective analysis shows that increased supply of enterally administered amino acids was associated with a significant increase in plasma BCAA and Tyr, and Trp with the exception of Phe. Despite this dose-dependent effect, enteral nutrition was insufficient to normalize plasma BCAA. Thus, higher amounts of BCAA in the enteral nutrition formula appear to be necessary. Based on the current analysis, however, a more aggressive increase in plasma BCAA level might be off-set by the observed increase in ICP and decreased $\mathrm{SjvO}_{2}$ and reported neuropsychologic alterations (Scarnà et al. 2005, Fernstrom and Fernstrom 2007). A prospective study is required to identify the required dose and assess possible dose dependent BCAA-mediated effects on ICP and $\mathrm{SjvO}_{2}$. As suggested by the current plasma profile it does not appear necessary to increase the amount of AAA in the enteral nutrition formula as plasma AAA levels were comparable to healthy volunteers and even significantly increased over time. However, the present data showing a beneficial impact of Phe reflected by decreased ICP and increased $\mathrm{SjvO}_{2}$ suggest that an increase in plasma Phe levels might be useful. This hypothesis must be investigated in a prospective study.

Persistently decreased plasma amino acid levels

As reported by Aquilani et al. (2003) and Borsheim et al. (2007), plasma amino acid levels remain decreased during 
the posttraumatic rehabilitation phase between 1 and 22 months after trauma. Based on this data, high energy nutritional support $(32.5 \mathrm{kcal} / \mathrm{kg})$ maintained or improved the patients' nutritional status without, however, correcting plasma amino acid imbalances. This, in turn, suggests to adapt the composition of the nutritional support based on the individual plasma levels to correct underlying deficiency (Aquilani et al. 2003) which is in line with results published by Borsheim et al. (2007) showing that persistently decreased amino acids as e.g., valine can be significantly increased by oral supplementation. Whether the significantly elevated plasma amino acid levels achieved by day 14 in the presently investigated TBI patients persisted thereafter and improved neurologic recovery during the rehabilitation phase cannot be determined by the present study. Prospective studies are required to identify an optimal composition of the enteral (and parenteral) nutrition to convey beneficial changes during the early posttraumatic and rehabilitative phase. In this context, optimized nutritional support could improve neuropsychologic recovery and decrease rate of depression and posttraumatic parkinsonism due to increased cerebral serotonin and cerebral dopamine synthesis by elevating plasma Trp, Tyr and Phe levels and increasing cerebral Trp, Tyr and Phe uptake, respectively. In addition, improved muscle protein synthesis related to elevated plasma and extracellular amino acid levels should facilitate quicker physical rehabilitation (Bohé et al. 2003).

\section{Study limitations and methodological considerations}

Comparing jugular venous amino acids taken from patients with peripheral venous amino acids obtained in volunteers is difficult as peripheral venous values reflect changes in skeletal muscle metabolism and jugular venous levels are influenced by cerebral metabolism. For technical reasons, however, cannulation of peripheral veins in patients is difficult due to peripheral edema and an increased risk of phlebitis which will off-set repetitive measurements and impair adequate interpretation of dynamic changes over time. More detailed investigations aimed at assessing the release and uptake of amino acids from skeletal muscle of the arm in these sedated critically ill patients are necessary to determine if amino acids taken from the cubital vein can be used as a reference values for jugular venous levels. In theory, the small muscle mass of the arm in immobilized deeply sedated patients should only marginally influence the peripheral venous levels. The fact that volunteers did not agree to arterial blood sampling does not allow to assess the influence of muscle metabolism reflected by changes in blood taken from the radial artery in patients. However, arterial plasma taken from femoral artery as performed in daily routine does not allow interpretation of the influence of muscle on changes determined in cubital venous blood. Separate investigations requiring arterial and internal jugular venous and peripheral venous cannulation in healthy volunteers are required to address the fundamental issue of possible site-specific differences in blood amino acid composition.

The difference in feeding state, i.e., overnight fasting in healthy volunteers living on their regular protein-based diet compared to continuous enteral nutrition in patients might also account for the observed significant differences. As shown by Riggio et al. (1989), the presently observed increase in venous plasma leucine, isoleucine, and valine levels in healthy volunteers could imply a lack in protein intake. However, the simultaneous significant decrease in plasma tyrosine, phenylalanine, and tryptophan levels in healthy volunteers compared to patients investigated in the present study excludes a lack in protein ingestion from prolonged fasting. According to the results published by Riggio et al. (1989), only prolonged protein-free fasting exceeding 2 days will increase plasma BCAA and AAA amino acid levels. The cubital venous plasma BCAA and AAA levels determined in healthy volunteers of the present study are similar to levels reported by Riggio et al. (1989) in volunteers on a regular protein-based diet. This, in turn, suggests that the plasma pattern observed in the presently investigated patients reflects underlying pathophysiology e.g., related to TBI, critical illness with its specific hormonal alterations during pharmacologic coma, and continuous enteral nutrition.

Whether increases in one subset of plasma amino acids are balanced by the decrease in other amino acids to maintain constant levels of overall amino acid concentrations as reviewed by Feigin et al. (1971) remains unclear. However, the fact that both plasma BCAA and AAA levels were significantly elevated by increased enteral nutrition excludes a compensatory mutual regulation at least in these investigated amino acids. Regulatory influences mediated by these amino acids on other amino acids as e.g., methionine and threonine cannot be determined by the present study (Shikata et al. 2010).

To correct for possible circadian changes with reduced plasma levels during the morning hours following an overnight fasting, plasma samples were drawn between 08:00 and 09:00 a.m. in healthy volunteers and patients, respectively. Whether a normal circadian profile is preserved in patients subjected to pharmacologic coma is unclear as a change in sleep-wakefulness pattern has been shown to alter the plasma amino acid rhythmicity as reviewed by Feigin et al. (1971).

Detailed possible impact of dynamic changes in underlying treatment effects on ICP and CPP cannot be assessed by the present investigations. To minimize potential 
interferences, patients requiring barbiturates and aggressive cooling were excluded. On average, ICP, $\mathrm{CPP}$ and $\mathrm{paCO}_{2}$ were comparable during the first and second week (Table 2). The therapy intensity level was similar in both weeks, excluding dramatic worsening requiring most aggressive treatment options as e.g., barbiturate coma and craniectomy. Owing to underlying therapeutic interventions, ICP was predominantly maintained below $20 \mathrm{mmHg}$. These interventions, in turn, might interfere with the correct interpretation of the impact of BCAA and AAA on ICP and $\mathrm{SjvO}_{2}$. Based on the observed significant influence of plasma amino acids on ICP and $\mathrm{SjvO}_{2}$ despite underlying treatment effects, we may assume that this response might have been even more obvious without the therapeutic interventions. A detailed prospective study including larger patient number including multiparametric analysis is required to address the impact of enteral nutrition with its specific amino acid composition on brain metabolism and brain-specific parameters as e.g., ICP, $\mathrm{SjvO}_{2}$. While (Oertel et al. (2009) were able to demonstrate significant positive influence of protein-rich diet in neurosurgical patients without, however, addressing the individual amino acids, Rossetti et al. (2008) were able to show significant influence of increased plasma amino acids on cognitive functions without, however, defining the impact of BCAA.

\section{Conclusions}

Critically ill patients suffering from severe TBI requiring continuous pharmacologic coma and receiving continuous enteral nutrition showed significantly reduced jugular venous plasma Ile, Leu, and Val levels and significantly increased jugular venous plasma Phe and Tyr levels compared to cubital venous plasma in healthy controls. This study suggests that enteral nutrition failed to normalize plasma BCAA levels despite a significant dose-dependent increase in plasma BCAA and AAA. Contrary to the initial assumption that elevated AAA levels are detrimental, only increased plasma Phe levels were associated with beneficial signs in terms of decreased ICP and reduced cerebral oxygen consumption reflected by increased $\mathrm{SjvO}_{2}$. In fact, increased jugular venous BCAA levels were associated with increased ICP and decreased $\mathrm{SjvO}_{2}$. Prospective studies are required to determine a dose-dependent effect of enteral nutrition on plasma amino acids and the potential Phe- and BCAA-mediated effects as observed in the current retrospective analysis.

Acknowledgments The help of the nursing staff in collecting plasma samples is gratefully acknowledged. The study was supported by grants from the Swiss National Science Foundation (SNF) and the SUVA Fonds to JFS.

\section{References}

Aquilani R, Iadarola P, Contardi A, Boselli M, Verri M, Pastoris O, Boschi F, Arcidiaco P, Viglio S (2005) Branched-chain amino acids enhance the cognitive recovery of patients with severe traumatic brain injury. Arch Phys Med Rehabil 86: $1729-1735$

Askanazi J, Furst P, Michelsen CB, Elwyn DH, Vinnars E, Gump FE, Stinchfield FE, Kinney JM (1980a) Muscle and plasma amino acids after injury: hypocaloric glucose vs. amino acid infusion. Ann Surg 191:465-472

Askanazi J, Carpentier YA, Michelsen CB, Elwyn DH, Furst P, Kantrowitz LR, Gump FE, Kinney JM (1980b) Muscle and plasma amino acids following injury. Influence of intercurrent infection. Ann Surg 192:78-85

Avruch J, Long X, Ortiz-Vega S, Rapley J, Papageorgiou A, Dai N (2009) Amino acid regulation of TOR complex 1. Am J Physiol Endocrinol Metab 296:592-602

Basler T, Meier-Hellmann A, Bredle D, Reinhart K (2002) Amino acid imbalance early in septic encephalopathy. Intensive Care Med 28:293-298

Blau N, van Spronsen FJ, Levy HL (2010) Phenylketonuria. Lancet 376:1417-1427

Blomstrand E, Møller K, Secher NH, Nybo L (2005) Effect of carbohydrate ingestion on brain exchange of amino acids during sustained exercise in human subjects. Acta Physiol Scand 185:203-209

Bohé J, Low A, Wolfe RR, Rennie MJ (2003) Human muscle protein synthesis is modulated by extracellular, not intramuscular amino acid availability: a dose-response study. J Physiol 552:315324

Cangiano C, Farber MO, Cardelli-Cangiano P, Rossi-Fanelli F, Cascino A, Capocaccia L, Cockerill EM, Manfredi F (1982) Plasma levels of false neurotransmitters across the brain in portal-systemic encephalopathy. Eur J Clin Invest 12:15-21

Chaplin ER, Goldberg AL, Diamond I (1976) Leucine oxidation in brain slices and nerve endings. J Neurochem 26:701-707

Daubert EA, Condron BG (2010) Serotonin: a regulator of neuronal morphology and circuitry. Trends Neurosci 33:424-434

Dejong CH, van de Poll MC, Soeters PB, Jalan R, Olde Damink SW (2007) Aromatic amino acid metabolism during liver failure. J Nutr 137(6 Suppl 1):1579S-1585S

Feigin RD, Beisel WR, Wannemacher RW Jr (1971) Rhythmicity of plasma amino acids and relation to dietary intake. Am J Clin Nutr 24:329-341

Fernstrom JD (2000) Can nutrient supplements modify brain function? Am J Clin Nutr 71(6 Suppl):1669S-1675S

Fernstrom JD (2005) Branched-chain amino acids and brain function. J Nutr 135(6 Suppl):1539S-1546S

Fernstrom JD, Fernstrom MH (2007) Tyrosine, phenylalanine, and catecholamine synthesis and function in the brain. J Nutr 137((6 Suppl 1)):1539S-1547S

Fischer JE, Rosen HM, Ebeid AM, James JH, Keane JM, Soeters PB (1976) The effect of normalization of plasma amino acids on hepatic encephalopathy in man. Surgery 80(1):77-91

Freund HR, Ryan JA Jr, Fischer JE (1978) Amino acid derangements in patients with sepsis: treatment with branched chain amino acid rich infusions. Ann Surg 188:423-430

Freund H, Atamian S, Holroyde J, Fischer JE (1979) Plasma amino acids as predictors of the severity and outcome of sepsis. Ann Surg 190:571-576

Freund H, Dienstag J, Lehrich J, Yoshimura N, Bradford RR, Rosen H, Atamian S, Slemmer E, Holroyde J, Fischer JE (1982) Infusion of branched-chain enriched amino acid solution in patients with hepatic encephalopathy. Ann Surg 196:209-220 
Holecek M (2010) Three targets of branched-chain amino acid supplementation in the treatment of liver disease. Nutrition 26:482-490

Lieberman HR (2003) Nutrition, brain function and cognitive performance. Appetite 40:245-254

Meier C, Ristic Z, Klauser S, Verrey F (2002) Activation of system L heterodimeric amino acid exchangers by intracellular substrates. EMBO J 21:580-589

Miyazaki T, Matsuzaki Y, Karube M, Bouscarel B, Miyakawa S, Tanaka N (2003) Amino acid ratios in plasma and tissues in a rat model of liver cirrhosis before and after exercise. Hepatol Res 27:230-237

Oertel MF, Hauenschild A, Gruenschlaeger J, Mueller B, Scharbrodt W, Boeker DK (2009) Parenteral and enteral nutrition in the management of neurosurgical patients in the intensive care unit. J Clin Neurosci 16:1161-1167

Petersen SR, Jeevanandam M, Holaday NJ, Lubhan CL (1996) Arterial-jugular vein free amino acid levels in patients with head injuries: important role of glutamine in cerebral nitrogen metabolism. J Trauma 41:687-694

Riggio O, Merli M, Pièche U, Romiti A, Pasqualetti P, Coppola A, Danese D, Cugini P, Capocaccia L (1989) Circadian rhythmicity of plasma amino acid variations in healthy subjects. Recenti Prog Med 80(11):591-593

Roberts LM, Black DS, Raman C, Woodford K, Zhou M, Haggerty JE, Yan AT, Cwirla SE, Grindstaff KK (2008) Subcellular localization of transporters along the rat blood-brain barrier and blood-cerebral-spinal fluid barrier by in vivo biotinylation. Neuroscience 155:423-438

Robertson CS, Gopinath SP, Goodman JC, Contant CF, Valadka AB, Narayan RK (1995) $\mathrm{SjvO}_{2}$ monitoring in head-injured patients. J Neurotrauma 12:891-896

Rossetti P, Porcellati F, Busciantella Ricci N, Candeloro P, Cioli P, Nair KS, Santeusanio F, Bolli GB, Fanelli CG (2008) Effect of oral amino acids on counterregulatory responses and cognitive function during insulin-induced hypoglycemia in nondiabetic and type 1 diabetic people. Diabetes 57:1905-1917

Scarnà A, McTavish SF, Cowen PJ, Goodwin GM, Rogers RD (2005) The effects of a branched chain amino acid mixture supplemented with tryptophan on biochemical indices of neurotransmitter function and decision-making. Psychopharmacology (Berl) 179:761-768

Shikata N, Maki Y, Nakatsui M, Mori M, Noguchi Y, Yoshida S, Takahashi M, Kondo N, Okamoto M (2010) Determining important regulatory relations of amino acids from dynamic network analysis of plasma amino acids. Amino Acids 38:179-187

Stinnett JD, Alexander JW, Watanabe C, MacMillan BG, Fischer JE, Morris MJ, Trocki O, Miskell P, Edwards L, James H (1982) Plasma and skeletal muscle amino acids following severe burn injury in patients and experimental animals. Ann Surg 195(1):75-89

Stover JF (2011) Actual evidence for neuromonitoring-guided intensive care following severe traumatic brain injury. Swiss Med Wkly 141:w13245

Stover JF, Steiger P, Stocker R (2005) Treating intracranial hypertension in patients with severe traumatic brain injury during neurointensive care. Eur J Trauma 4:308-330

Suzuki M, Kudo A, Sugawara A, Yoshida K, Kubo Y, Suzuki T, Ogasawara K, Doi M, Ogawa A (2002) Amino acid concentrations in the blood of the jugular vein and peripheral artery after traumatic brain injury: decreased release of glutamate into the jugular vein in the early phase. J Neurotrauma 19:285-292

Valerio A, D'Antona G, Nisoli E (2011) Branched-chain amino acids, mitochondrial biogenesis, and healthspan: an evolutionary perspective. Aging (Albany NY) 3:464-478

Vente JP, von Meyenfeldt MF, van Eijk HM, van Berlo CL, Gouma DJ, van der Linden CJ, Soeters PB (1989) Plasma-amino acid profiles in sepsis and stress. Ann Surg 209:57-62

Verrey F (2003) System L: heteromeric exchangers of large, neutral amino acids involved in directional transport. Pflugers Arch 445:529-533

Vuille-Dit-Bille RN, Ha-Huy R, Tanner M, Stover JF (2011) Changes in calculated arterio-jugular venous glutamate difference and $\mathrm{SjvO}_{2}$ in patients with severe traumatic brain injury. Minerva Anestesiol 77:870-876 